\title{
Renal imaging: a comparison of radionuclide, ultrasound, and computed tomographic scanning in investigation of renal space-occupying lesions
}

\author{
P H O'REILLY, D E OSBORN, H J TESTA, D L ASBURY, J J K BEST, R J BARNARD
}

\begin{abstract}
Two studies were carried out in which 27 and 23 patients respectively with renal space-occupying lesions were assessed by different techniques and the results compared. Instead of proceeding to renal arteriography after the lesion had been found on urography, radionuclide and ultrasound scanning were used in the first study to clarify the nature of the lesions, while in the second study computed tomography was used as well. Results were good with all three methods, although ultrasonography and radionuclide scanning cannot resolve lesions of under $2 \mathrm{~cm}$ in diameter and the radiation dose with computed tomography is similar to that used in renal arteriography.
\end{abstract}

Probably the best method of evaluating renal spaceoccupying lesions after urography is to use both ultrasound and radionuclide scanning. If further information is required computed tomography or arteriography is indicated.

\section{Introduction}

Clinicians can now choose between ultrasonography, radionuclide imaging, computed tomography, arteriography, and cyst puncture to evaluate renal space-occupying lesions detected on excretion urography. In contrast to arteriography and cyst puncture, ultrasonography, radionuclide imaging, and computed tomography are non-invasive, and all have their individual advantages and disadvantages. We describe the results of two studies carried out to evaluate these techniques and to determine their role in the investigation of a suspected renal mass lesion.

\section{Study 1}

PATIENTS AND METHODS

In the first study we compared results of radionuclide scanning and ultrasonography in 27 consecutive patients found to have renal mass lesions on excretion urography. The patients comprised 20 men and seven women aged 33-90 years (mean 60 years).

Dynamic radionuclide scans were performed using $10 \mathrm{mCi}$ of ${ }^{99 \mathrm{~m}} \mathrm{Tc}$-gluconate and a gammacamera computer system (NE Mk III Digital Equipment Co PDP 12 computer; G E Radicamera with Med II system or Elscint Dymax LF). Imaging was performed in the posterior projection with the patient sitting. The methodology has

\footnotetext{
Departments of Urology and Radiology, University Hospital of South Manchester, Manchester M20 8LR, and Department of Nuclear Medicine, Manchester Royal Infirmary, Manchester M13 9WL

P H O'REILLY, MD, FRCS, senior registrar in urology

D E OSBORN, MS, FRCS, senior registrar in urology

H J TESTA, PHD, MD, consultant in nuclear medicine

D L ASBURY, FFR, DMRD, consultant radiologist

J J K BEST, FRCR, MRCP, senior lecturer in radiology (present appointment: Forbes professor of radiology, Edinburgh Royal Infirmary)

R J BARNARD, FRCS, FRCSE, consultant urologist
}

been reported previously. ${ }^{1}$ In brief, $10 \mathrm{mCi}$ of the radiopharmaceutical was injected through a Butterfly (Abbott) cannula into a suitable vein and rapidly flushed through with $10 \mathrm{ml}$ of saline. A radionuclide renal angiogram showing areas of increased or decreased blood flow was obtained by collecting pictures on the gammacamera at one-second intervals from five to 50 seconds after injection. Analogue pictures were taken simultaneously at five-second intervals for 30 seconds. Parenchymal images were obtained by collecting two-minute frames at two, 10, and 20 minutes. Analogue pictures of 400000 counts were also recorded simultaneously at two, 10 and 20 minutes. The vascular and parenchymal images were then compared to assess the nature of any abnormality found.

Ultrasound examination was carried out with a Kretz Combison A and B scan system with grey-scale modification. This was done in a different hospital from the radionuclide scanning and by a different investigator. Each investigator had access to the patients' original urograms but not to each other's results. The ultrasound examinations were performed with the patient prone. Arachis oil was used to ensure satisfactory acoustic coupling. Images were obtained with a $2 \mathrm{MHz}$ non-focused transducer, and cystic lesions were confirmed using lesspenetrating energy from a $4 \mathrm{MHz}$ probe. Each kidney was examined by multiple transverse and longitudinal sections, and selected screen images were recorded by Polaroid film. All examinations were performed by one observer. Space-occupying lesions were considered to be cystic if they showed clear-cut margins, a homogenous anechoic interior, and good transmission of sound to their distal margins. In contrast, solid masses had less well-defined margins and an internal pattern of echoes producing greater attenuation of the sound beams.

\section{RESULTS}

Table I summarises the results. The final diagnosis was made at operation in all the patients with adenocarcinoma, the patient with xanthogranulomatous pyelonephritis, and two of the patients with renal cysts. Two further cysts were aspirated. In the remaining 10

TABLE I-Results of combined use of radionuclide and ultrasound scanning in the investigation of renal space-occupying lesions (study 1)

\begin{tabular}{|c|c|c|c|c|c|}
\hline \multirow{2}{*}{ Final diagnosis } & \multirow{2}{*}{$\begin{array}{l}\text { No of } \\
\text { cases }\end{array}$} & \multicolumn{2}{|c|}{ Radionuclide scan } & \multicolumn{2}{|c|}{ Ultrasound scan } \\
\hline & & Diagnosis & $\overline{\text { No }}$ & Diagnosis & $\overline{\text { No }}$ \\
\hline Renal cyst & 14 & Avascular & 14 & $\left\{\begin{array}{l}\text { Cystic } \\
\text { Not vis }\end{array}\right.$ & $\begin{array}{r}12 \\
\text { ed } 2\end{array}$ \\
\hline Renal adenocarcinoma & 10 & $\left\{\begin{array}{l}\text { Vascular } \\
\text { Avascular }\end{array}\right.$ & $\begin{array}{l}8 \\
2\end{array}$ & $\begin{array}{l}\text { Solid } \\
\text { Cystic }\end{array}$ & \\
\hline $\begin{array}{l}\text { Pseudotumour } \\
\text { Xanthogranulomatous }\end{array}$ & 2 & Normal & 2 & Normal & 2 \\
\hline pyelonephritis & 1 & Vascular & 1 & Solid & 1 \\
\hline
\end{tabular}

patients with cysts the diagnosis was considered to be so certain on the basis of the two non-invasive procedures and intravenous urography that any further procedures were considered to be unnecessary. Renal arteriography was not performed routinely but was carried out in two patients to confirm the diagnosis of pseudotumour.

Radionuclide scanning showed an avascular lesion in all of the 14 patients with cysts. It showed a tumour circulation in eight of the 10 patients with hypernephroma, but in two patients with necrotic lesions it showed avascular appearances. Ultrasonography showed cystic appearances in 12 of the 14 patients with cysts: the two other masses were not visualised. It correctly diagnosed nine of the 10 hypernephromas, interpreting the tenth as cystic. Both procedures correctly showed the xanthogranulomatous pyelonephritis to be a solid vascular lesion and the pseudotumours to be normal variants. 
Study 2

\section{PATIENTS AND METHODS}

In this study computed tomography was used in addition to radionuclide scanning and ultrasonography to evaluate lesions found on urography. Twenty-four lesions in 23 patients were evaluated, the patients comprising 15 men and eight women aged 30-78 years (mean 62 years). Radionuclide scanning and ultrasonography were performed blind as previously described. The results of computed tomography could not be evaluated blind, and the case notes and results of previous investigations were sometimes available at the time of scanning. Computed tomography was carried out using an EMI 5005 machine. The patients were scanned through the kidneys at $1-\mathrm{cm}$ intervals with a linear resolution of $1 \mathrm{~mm}$ and a slice thickness of $13 \mathrm{~mm}$. The scans were made at $140 \mathrm{kV}$ peak and $28 \mathrm{~mA}$ at normal scan speeds $(20 \mathrm{~s})$ with the patients holding their breath on inspiration. Computed tomographic angiography was subsequently performed: a single scan was obtained using $50 \mathrm{ml}$ sodium iothalamate (Conray 420 ) and scans at several levels were obtained after contrast enhancement.

\section{RESULTS}

Table II summarises the results. The final diagnosis was established by nephrectomy in the patients with adenocarcinoma, transitional-cel tumour of the renal pelvis, xanthogranulomatous pyelonephritis, and haemorrhagic renal cyst. Needle aspiration was performed in two patients with cysts: this confirmed the diagnosis in one, but in the other surgical exploration was required since the cyst wall appeared irregular after injection of contrast. In one patient, who had bilatera secondary tumours from a bronchogenic primary, the final diagnosis was made by renal arteriography. In the remaining patients these three investigations and urography so firmly indicated the benign nature of the lesion that no further confirmation was sought.

Computed tomography gave the correct diagnosis in all patients with hypernephroma, the patients with bilateral renal metastases, and the patient with transitional-cell tumour of the renal pelvis. The haemorrhagic renal cyst was reported as being a neoplasm or haemorrhagic cyst. The xanthogranulomatous pyelonephritis was confidently reported as a hypernephroma. In all other patients diagnoses obtained with computed tomography were correct. Ultrasound scanning yielded correct results in all patients with hypernephroma and the patient with transitional-cell tumour of the renal pelvis. In the patient with bilateral renal metastases one metastasis 'was missed. Of the seven renal cysts, three were misinterpreted as being solid. Radionuclide scanning indicated a space-occupying lesion in the parenchymal studies in all the patients with hypernephroma, but in three the initial dynamic vascular studies failed to show a definite tumour circulation. This was also the case in one of the patients with renal metastases. In five of the seven patients with renal cysts an avascular filling defect was seen, and in the patient with a parapelvic cyst an enlarged pelvis was evident. In one patient with a poorly functioning kidney and transitional-cell tumour no satisfactory image was obtained.

\section{Discussion}

Fewer than $75 \%$ of excretion urograms are adequate for establishing the nature of renal space-occupying lesions, and in cases in which radiographic and tissue diagnoses have been compared the false-negative rate (cancer being misdiagnosed as benign) has been over $10 \% \cdot{ }^{2}$ After urography, therefore, further investigation of renal mass lesions is necessary. Radionuclide scanning, ultrasonography, and computed tomography are not all generally available, but it is important to compare their individual qualities to assess their relative merits and particular roles in patient management. The tests, however, reflect different physiological and physical characteristics of the kidney and are thus complementary rather than competitive. Ultrasonography depends on the reflection and impedance of projected sound waves whereas radionuclide scanning shows renal vasculature in the form of a dynamic angiogram and, later, parenchymal images from cortical retention of the radiopharmaceutical. Computed tomography assesses the morphological tissue structure of the body in a detailed cross-sectional axis.

For most clinicians ultrasonography is the most readily available of these three procedures. Sherwood reported its accuracy as being $98 \%$ for renal cysts and $86 \%$ for renal tumours. ${ }^{3}$ The present series yielded results of $76 \%$ for cysts and $95 \%$ for tumours. The technique represents a valuable development in renal imaging. Its limitations are that it is highly operator dependent and has a $2-\mathrm{cm}$ limit of operational resolution. Some of the cysts in the present series were this size, which may account for the reduced accuracy of ultrasound diagnosis of cysts compared with other reports. In contrast the renal tumours tended to be larger and thus more readily defined. Other problems that may arise with ultrasound examination are connected with renal movement during scanning, changes of position of overlying bowel, and bony interference with highand low-lying kidneys. In addition, degenerating and necrotic tumours may be misinterpreted as being transsonic. Nevertheless, ultrasonography is a useful, simple, rapid, and non-invasive test. It does not require renal function for visualisation, no complications have been reported from its use, and no form of radiation source is necessary.

With the recent expansion of facilities for nuclear medicine radionuclide scintigraphy has become widely available. A study of its use in renal space-occupying disease suggested an accuracy of $96 \%$ for renal cysts and $81 \%$ for hypernephroma (though falling to only $17 \%$ for transitional-cell tumours of the renal pelvis, which tend to be predominantly avascular). ${ }^{1}$ In the present series space-occupying lesions were confirmed in all but two cases. They were shown to be avascular in $90 \%$ of cysts and vascular in $77 \%$ of primary renal tumours. No tumour circulation was seen in the relatively avascular transitional-cell and metastatic tumours. The technique is not as operator dependent as ultrasonography. Although it requires venepuncture, it is similarly simple to perform, quick, and without documented complication. The radiation dose is small, about $1.7 \mathrm{rads}$ being the dose to the kidneys and 0.09 rads the whole-body dose. The technique will not resolve lesions less than $2 \mathrm{~cm}$ in diameter, however, may misinterpret necrotic carcinomas as cystic, and, unlike ultrasonography, depends on renal function for visualisation.

In view of the small but definite failure of ultrasonography and radionuclide examination when used alone for renal imaging our present practice in this centre, where both are readily available, is to combine them in evaluating renal space-occupying lesions. In this way information on the structure and vascularity of the lesion may be obtained. This policy can be particularly useful in

TABLE II-Results using radionuclide, ultrasound, and computed tomographic scanning in the investigation of renal space-occupying lesions (study 2)

\begin{tabular}{|c|c|c|c|c|c|c|c|}
\hline \multirow{2}{*}{ Final diagnosis } & \multirow{2}{*}{$\begin{array}{l}\text { No of } \\
\text { cases }\end{array}$} & \multicolumn{2}{|l|}{ Radionuclide scan } & \multicolumn{2}{|l|}{ Ultrasound scan } & \multicolumn{2}{|c|}{ Computed tomographic scan } \\
\hline & & Result & No & Result & No & Result & No \\
\hline Renal adenocarcinoma & 12 & $\left\{\begin{array}{l}\text { Vascular } \\
\text { Avascular } \\
\text { Equivocal }\end{array}\right.$ & $\begin{array}{l}9 \\
2 \\
1\end{array}$ & Solid & 12 & Neoplasm & 12 \\
\hline Renal cyst & 7 & $\left\{\begin{array}{l}\text { Avascular } \\
\text { No lesion }\end{array}\right.$ & $\begin{array}{l}5 \\
2\end{array}$ & $\begin{array}{l}\text { Cystic } \\
\text { Solid }\end{array}$ & $\begin{array}{l}4 \\
3\end{array}$ & $\begin{array}{l}\text { Cystic } \\
\text { Haemorrhagic cyst/neoplasm }\end{array}$ & $\begin{array}{l}6 \\
1\end{array}$ \\
\hline Transitional cell tumour of renal pelvis & is 1 & Non-functioning kidney & 1 & Solid lesion in renal pelvis & 1 & Neoplasm & 1 \\
\hline Bilateral metastatic tumours & 1 & $\left\{\begin{array}{l}\text { Avascular space-occupying lesion } \\
\text { Normal }\end{array}\right.$ & $\begin{array}{l}1 \\
1\end{array}$ & $\begin{array}{l}\text { Solid tumour } \\
\text { Normal }\end{array}$ & $\begin{array}{l}1 \\
1\end{array}$ & Bilateral neoplasms & 1 \\
\hline Xanthogranulomatous pyelonephritis & 1 & Avascular lesion of kidney & 1 & ? Tumour ? Pyonephrosis & 1 & Hypernephroma & 1 \\
\hline Parapelvic cyst & 1 & Enlarged renal pelvis & 1 & Normal & 1 & Parapelvic cyst & 1 \\
\hline
\end{tabular}


elderly patients with asymptomatic renal space-occupying lesions found incidentally in the investigation of lower-tract disorders. In such cases when ultrasonography indicates a cyst that is confirmed to be avascular by radionuclide scanning, the likelihood of error is small, and in our series of 43 renal adenocarcinomas and cysts there was no case in which the results of the two examinations agreed in error. A renal cyst may, of course, be confirmed by cyst puncture, ${ }^{4}$ but this has a complication rate of $0.77-3.0 \%$, which is unacceptably high for asymptomatic lesions in elderly patients. ${ }^{5}$ When both ultrasonography and radionuclide scanning suggest a cystic lesion cyst puncture is unnecessary for purely diagnostic purposes. For complex renal space-occupying lesions further examination may be required, and over the past five years computed tomography has been used as a non-invasive test to fulfil this role.

The results achieved in the present study with computed tomography (though this was not done blind) were good. No

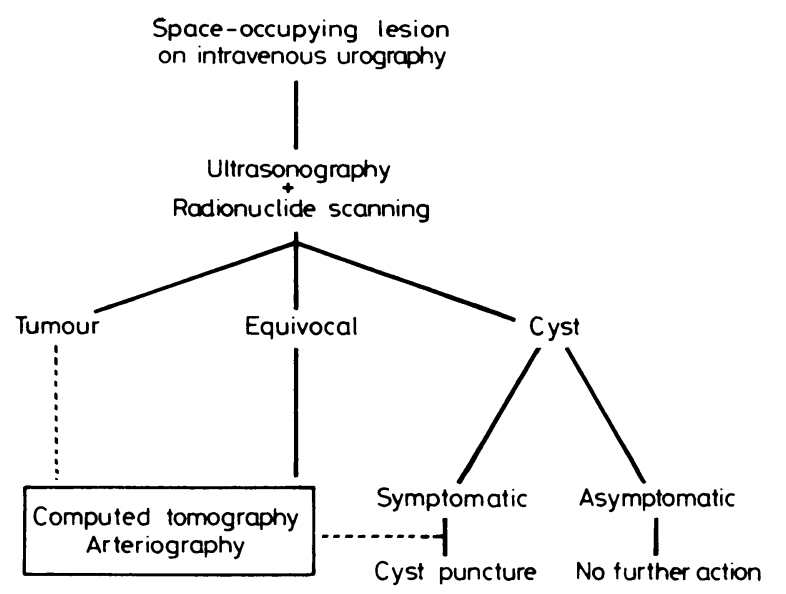

Protocol in south Manchester for investigation of renal spaceoccupying lesions.

false-negative results were obtained, and only two false-positive results (haemorrhagic cyst and xanthogranulomatous pyelonephritis): in both of these the diagnosis remained unclear until operation. Others have reported similarly good results with computed tomography ${ }^{6}$ and have suggested that cyst puncture may now be avoided in most cases ${ }^{7}$ since computed tomography duplicates the information available from ultrasonography and cyst puncture. ${ }^{8}$ In the United Kingdom computed tomography, when available and of proved accuracy, is probably preferred to invasion, particularly if a local expert in cyst puncture is not available. The problems of the technique are its initial expense and lack of general availability. The radiation dose is greater than for radionuclide scanning, the maximum entry dose for a 20second single section being 1.5 rads, while seven adjacent sections done at $13-\mathrm{mm}$ spacing produce a pile-up factor of 2.9 rads maximum entry dose. ${ }^{9}$ This is about the same as the dose used in renal arteriography.

Renal arteriography remains the final examination for renal space-occupying lesions and renal vasculature in many hospitals. Even this, however, has major $(0.71 \%)$ and minor $(2.9 \%)$ complications. ${ }^{2}$ False-negative and false-positive results are $3.6 \%$ and $2.9 \%$ respectively. ${ }^{2}$ Errors may occur with hypovascular and avascular tumours, while granulomas, abscesses, and angiomyolipomas may all be hypervascular and mimic tumours. These problems are illustrated by a report from Ambrose et al. ${ }^{10}$ In a series of 55 kidneys that appeared to contain avascular cysts on arteriography five $(9 \cdot 1 \%)$ were found at operation to harbour previously undetected renal neoplasms. ${ }^{11}$

In conclusion, we suggest that, when readily available, the combination of ultrasonography with radionuclide scanning provides a useful initial evaluation of renal space-occupying lesions after urography. In elderly patients with asymptomatic cysts no further invasive examination may be required. The recent results of using computed tomography have been impressive. The figure summarises the present practice in south Manchester. Despite these advances in renal imaging, however, it has to be recognised that the choice of investigation will be influenced by local resources, and even with all the available techniques to hand $5-8 \%{ }^{11}$ of renal mass lesions are still likely to defy preoperative diagnosis.

\section{References}

${ }^{1}$ O'Reilly PH, Shields RA, Testa HJ. Nuclear medicine in urology and nephrology. London and Boston: Butterworths, 1979.

2 Clayman RV, Williams RD, Fraley EE. The pursuit of the renal mass. N Engl f Med 1979;300:72-4.

${ }^{3}$ Sherwood T. Renal masses and ultrasound. Br Med F 1975;iv:682-5.

4 Isikoff MB, Guter M. Diagnostic imaging of the upper part of the abdomen. Surg Gynecol Obstet 1979;149:161-7.

${ }^{5}$ Lang EK. Renal cyst puncture and aspiration: a survey of complications. American fournal of Roentgenology 1977;128:723-7.

${ }^{6}$ Struyven J, Brion JP, Frederic N, Schulman CC. Computed tomography of the kidney. Brf Urol 1979;49:583-8.

${ }^{7}$ McLennan BL, Stanley RJ, Nelson GL, Levitt RG, Sagel SS. CT of the renal cyst. American fournal of Roentgenology 1979;139:671-5.

${ }^{8}$ Abrams HL, McNeil BJ. Medical implications of computed tomography. N Engl f Med 1978;298:255-61.

9 Isherwood I, Pullan BR, Ritchings RT. Radiation dose in neuroradiology procedures. Neuroradiology 1978;16:478-81.

10 Ambrose SS, Lewis EL, O'Brien DP, Walton KN, Ross JR. Unsuspected renal tumours associated with renal cysts. $\mathcal{F}$ Urol 1977;117:704-7.

${ }^{11}$ Murphy JB, Marshall FF. Renal cyst versus tumour. F Urol 1980;123: 566-70.

(Accepted 8 Fanuary 1981)
FENNEL. Every garden affords this so plentifully, that it needs no description.

One good old fashion is not yet left off, viz. to boil Fennel with fish; for it consumes that phlegmatic humour, which fish most plentifully afford and annoy the body with, though few that use it know wherefore they do it; I suppose the reason of its benefit this way is because it is an herb of Mercury, and under Virgo, and therefore bears antipathy to Pisces. Fennel is good to break wind, to provoke urine, and ease the pains of the stone, and helps to break it. The leaves or seed, boiled in barley water and drank are good for nurses, to increase their milk, and make it more wholesome for the child. The leaves, or rather the seeds, boiled in water, stays the hiccough, and takes away the loathings which oftentimes happen to the stomachs of sick and feverish persons and, allays the heat thereof. The seed boiled in wine and drank, is good for those that are bitten with serpents, or have eaten poisonous herbs, or mushrooms. The seed and the roots much more, help to open obstructions of the liver, spleen, and gall, and thereby help the painful and windy swellings of the spleen, and the yellow jaundice; as also the gout and cramps. The seed is of good use in medicines to help shortness of breath and wheezing by stopping of the lungs. It helps also to bring down the courses, and to cleanse the parts after delivery. The roots are of most use in physic drinks, and broth that are taken to cleanse the blood, to open obstructions of the liver, so provoke urine, and amend the ill colour in the face after sickness, and to cause a good habit through the body. Both leaves, seeds, and roots thereof are much used in drink or broth, to make people more lean that are too fat. The distilled water of the whole herb, or the condensate juice dissolved, but especially the natural juice, that in some counties issues out hereof of its own accord, dropped into the eyes, cleanses them from mists and films that hinder the sight. The sweet Fennel is much weaker in physical uses than the common Fennel. The wild Fennel is stronger and hotter than the tame, and therefore most powerful against the stone, but not so effectual to encrease milk, because of its dryness. (Nicholas Culpeper (1616-54) The Complete Herbal, 1850.) 